\title{
Econometric approach to modeling the global partnership between the Russian federation and the republic of Belarus in the manufacturing industry
}

\author{
Mikhail Petrov*, Leonid Serkov, and Konstantin Kozhov
}

Ural Branch of RAS, Yekaterinburg, Russian Federation

\begin{abstract}
The working hypothesis of the study is the postulate that the implementation of the global partnership of the Russian Federation and the Republic of Belarus should take place at the level of interregional interactions. The paper proposes the methodological approach and tools for assessing possible interregional interactions between the constituent entities of the Russian Federation and the Republic of Belarus in the manufacturing industry, as well as investigates the factors influencing this interaction. Data from the official statistical websites of Russia and Belarus for 84 subjects of the Russian Federation and the Republic of Belarus were used to calculate the studied indicators. At the first stage, the spatial distribution of the volume of output in the manufacturing sector of the regions of the Russian Federation and the Republic of Belarus is analyzed in order to assess the possibilities of interaction between these regions in this sector of the economy. When modeling, the Republic of Belarus is considered as a separate region within the Union State. A positive autocorrelation was established between the subjects of the Russian Federation and the Republic of Belarus using Moran's indices. At the second stage, the influence of economic, infrastructural and institutional factors on the indicator characterizing the degree of possible interaction of the regions of the Russian Federation with the Republic of Belarus in the manufacturing industry was studied. The influence of economic, infrastructural, and institutional factors on this indicator under study was studied using Beta regression. The use of this approach makes it possible to substantiate the priority areas of economic development of territories within the Union State, in particular, to search for centers of attraction of resources and spheres of their influence on the territory. The findings of this paper can be used in the preparation of strategies, programs, and schemes for the placement and development of industries taking into account the potential of a new level of integration of the economies of Russia and Belarus.
\end{abstract}

\footnotetext{
*Corresponding author: serkov.la@uiec.ru
} 


\section{Introduction}

The project of the Union State of the Russian Federation and the Republic of Belarus carries a lot of work to build mutually beneficial economic integration interstate relations. Interaction between the subjects of different countries promotes the active exchange of new knowledge, joint efforts in the search for new ideas, joint development of new solutions, acts as an important criterion for success in the field of innovation. In this context, cooperation between Russia and Belarus is of particular importance in the framework of foreign economic activity for both countries [1]. The development and signing of interstate and intergovernmental treaties and agreements on the entire spectrum of economic cooperation covered by the Union State is underway as part of strengthening the legal framework. At the same time, it is important to not only preserve the existing ones, but also to revive and create new technological chains and cooperative ties between enterprises of the two states, thereby mobilizing long-term factors contributing to economic integration.

The Union State receives a new priority, as the spatial development of the Belarusian economy from Kaliningrad to Kamchatka increases, which in turn stimulates the growth of the volume of goods of its own production produced at Russian enterprises that work in cooperation with the Belarusian industry. Therefore, the relevance of the study of economic, infrastructural and institutional factors affecting the change in the level of economic interaction between the subjects of the Russian Federation and the Republic of Belarus increases.

The paper [2] draws attention to the conflict between the national strategy of spatial development of Russia and its regional strategies. Since the implementation of the global partnership of the Russian Federation and the Republic of Belarus should take place at the level of interregional interactions, it is particularly relevant to develop tools for assessing these interactions. In the works $[3 ; 4]$ analyze methods for studying interterritorial relationships at both the regional and municipal levels and justifies the need to take into account the spatial autocorrelation of subjects.

It should be noted that studies in the above works, in the territorial aspect, were conducted on the regions that are part of the Russian Federation. Therefore, it is of interest to expand these studies to the level of territories located within the borders of the Union State of Russia and Belarus, as well as to improve the methodological approach by supplementing it with an analysis of the determinants of the spatial interaction of the regions of the Russian Federation and the Republic of Belarus.

In the Russian Federation and the Republic of Belarus the main share of industrial production falls on the manufacturing industry - mechanical engineering, metalworking, etc. Such representatives of the Belarusian mechanical engineering as BelAZ, MAZ, MTZ (Minsk Tractor Plant), MZKT (Minsk Wheel Tractor Plant) are widely known. Currently, the BelAZ plant has produced the latest BelAZ-75710 dump truck, which is the most powerful truck in the world with a particularly large load capacity of 450 tons, which uses all the latest achievements of science and technology. The production of such products at the Belarusian enterprise OAO "BelAZ" with the use of Russian-made components and the subsequent use of such high-tech equipment in the mining industry of Russia is a vivid example of effective economic cooperation between the two states within the Union State.

At the same time, in the context of the global partnership, interregional cooperation between the Russian Federation and the Republic of Belarus is an important factor in the development of industrial and social spheres, a source of attracting investment, expanding product sales markets, and implementing a policy of expanding and strengthening trade, economic, scientific, and technical ties in the field of innovation between the Russian Federation and the Republic of Belarus. Based on the above, the purpose and objective of 
the proposed publication is to analyze the possible interaction of the regions of the Russian Federation and Belarus in the manufacturing industry and to study the factors influencing this interaction.

\section{Research methods}

At the first stage of this paper, the spatial distribution of the volume of output in the manufacturing sector of the regions of the Russian Federation and the Republic of Belarus is studied in order to assess the possibilities of interaction between these regions in this sector of the economy. The presence of a possible spatial autocorrelation of interregional interaction of territories is tested using Moran indices [5].

The global $I_{m}$ and local (LISA) $I_{m i}$ indexes are used to identify spatial localization. $I_{m}$ takes values from -1 to 1 . If the result of the calculations is significant and positive, then we can assert about a positive spatial autocorrelation. In the economic sense, this corresponds to the cooperation of the constituent entities of the Russian Federation and the Republic of Belarus (in general) with similar levels of production. In the case of negative values, the territories are separated, and the neighboring regions differ significantly in this indicator. The local Moran index characterizes the degree of mutual influence of the volumes of products produced in the studied region on the indicators of other territories associated with this constituent entity.

The expression for calculating the global Moran's index of the distribution of the production volume in the manufacturing industry by the constituent entities of the Russian Federation and the Republic of Belarus (in general) $\left(I_{m}\right)$ has the following form:

$$
I_{m}=\frac{N}{S_{0}} \frac{\sum_{i=1}^{n} \sum_{j=1}^{m} w_{i j}\left(x_{i}-\mu\right)\left(x_{j}-\mu\right)}{\sum_{i=1}^{n}\left(x_{i}-\mu\right)^{2}}
$$

where $x_{i}$ is the analyzed production volume of region $i ; \mathrm{x}_{\mathrm{j}}$ is the analyzed production volume of region $j ; \mu$ is the average value of the analyzed production volume for all analyzed regions; $w_{i j}$ is an element of the matrix of spatial weights for regions $i$ and $j ; N$ is the number of analyzed regions; $S_{0}$ is the sum of all weights of the spatial matrix, $S_{0}=\sum_{i=1}^{n} \sum_{j=1}^{m} w_{i j}$.

An important indicator that characterizes the degree of mutual influence of production volumes in the manufacturing sector between two separate territories is the indicator $L I S A_{i j}=z_{i} z_{j} w_{i j}$, where $z_{i}, z_{j}-$ is the standardized deviations of production volumes of each individual region from the average value. This indicator is an ideal proxy variable for quantifying the degree of mutual influence, and it is this indicator that will be analyzed in the future (at the second stage) when describing the mutual influence of individual regions of the Russian Federation with the Republic of Belarus. 
At the second stage, the influence of economic, infrastructural and institutional factors on the indicator $L I S A_{i j}$, characterizing the degree of possible interaction of two territories in the manufacturing industry is investigated. In this case, the indicator $L I S A_{i j}$ was normalized to change it in the range from 0 to 1 and was a dependent variable. The explanatory variables were economic, infrastructural and institutional factors. The influence of the latter on the indicator $L I S A_{i j}$ was analyzed using Beta regression.

Beta regression [6] is used to assess the influence of various factors on the dependent variable, which varies in the range from 0 to 1 and obeys the Beta distribution with density

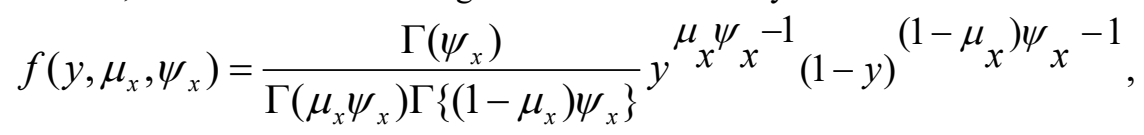

where the conditional mathematical expectation of the dependent variable for the given regressors $\mu_{x}=E(y \mid \mathbf{x})$ is related to the regressors $\mathbf{x}$ by means of the function $g\left(\mu_{x}\right)=\mathbf{x}^{\prime} \beta$, where $\mathbf{x}^{\prime}=\left(x_{i 1}, x_{i 2}, \ldots x_{i k}\right), i=1, \ldots n$ ( $i-$ - number of observations, $k$ - - number of regressors). The parameter $\psi_{x}$ takes into account the correlation between the regressors and the residual variance $\operatorname{VAR}(y \mid \mathbf{x})=\mu_{x}\left(1-\mu_{x}\right) /\left(1+\psi_{x}\right)$ and is associated with the regressors by means of a function $h\left(\psi_{x}\right)=\mathbf{x}^{\prime} \gamma$. The normal distribution functions, logistic functions, and doubly logarithmic functions are used as the link function $g\left(\mu_{x}\right)$. Logarithmic, linear and power functions are used as the link function $h\left(\psi_{x}\right)$. The Beta regression parameters are estimated using the maximum likelihood method.

\section{Results and discussion}

\subsection{Identification of the spatial features of the production volume distribution in the manufacturing industry in the regions of the Russian Federation and the Republic of Belarus}

The information basis of the study is the official statistics of Rosstat. To test spatial autocorrelation, this paper uses the following data for 2018 in the context of 84 regions of the Russian Federation and the Republic of Belarus: the production volume in the manufacturing sector (million rubles) and the gross regional product (million rubles).

The spatial features of the production volume distribution in the manufacturing industry by the subjects of the Russian Federation and the Republic of Belarus were identified using Moran indices. The presence of a positive autocorrelation of the production volume distribution in the manufacturing industry between all regions of the Russian Federation and the Republic of Belarus is confirmed by the positive value of the global Moran's index obtained during the study. The presence of a positive spatial autocorrelation indicates the potential for mutual influence of the Republic of Belarus with the regions of the Russian Federation in the manufacturing industry. This allows using the elements of the matrix of mutual influence of individual territories as a measure of the possible degree of interaction of the Republic of Belarus with Russian regions in the manufacturing industry. The spatial 
distribution of the indicator $L I S A_{1 j}$ (index 1 refers to the Republic of Belarus, the index $j$ refers to the regions of the Russian Federation) determines the mutual influence of all subjects of the Russian Federation with the Republic of Belarus. The distribution of positive and negative mutual influence of the Republic of Belarus with 84 subjects of the Russian Federation in the manufacturing sector for 2018 by indicator $L I S A_{1 j}$ is shown in Figure 1. The diagram shows the subjects of the Russian Federation with positive mutual influence with the Republic of Belarus in dark gray $\left(L I S A_{1 j}>0\right)$ and negative mutual influence in light gray. As a percentage, approximately $30 \%$ of the territories have a positive mutual influence and $70 \%$ - a negative one.

It should be noted that the Moran indices allow making only initial assumptions about the presence of spatial effects. For example, a positive value of the Moran index for the distribution of output in the manufacturing sector only means a positive impact on this indicator in a certain region of output in neighboring regions. At the same time, it remains unclear due to what factors this positive influence is ensured. To answer this question, we should establish a functional connection between the dependent and independent variables in the form of a regression model. Therefore, the next part of the article is devoted to the selection and evaluation of factors that affect the degree of interaction of the Republic of Belarus with 84 Russian regions in the manufacturing sector on the basis of the indicator $L I S A_{1 j}=z_{1} z_{j} w_{1 j}$.

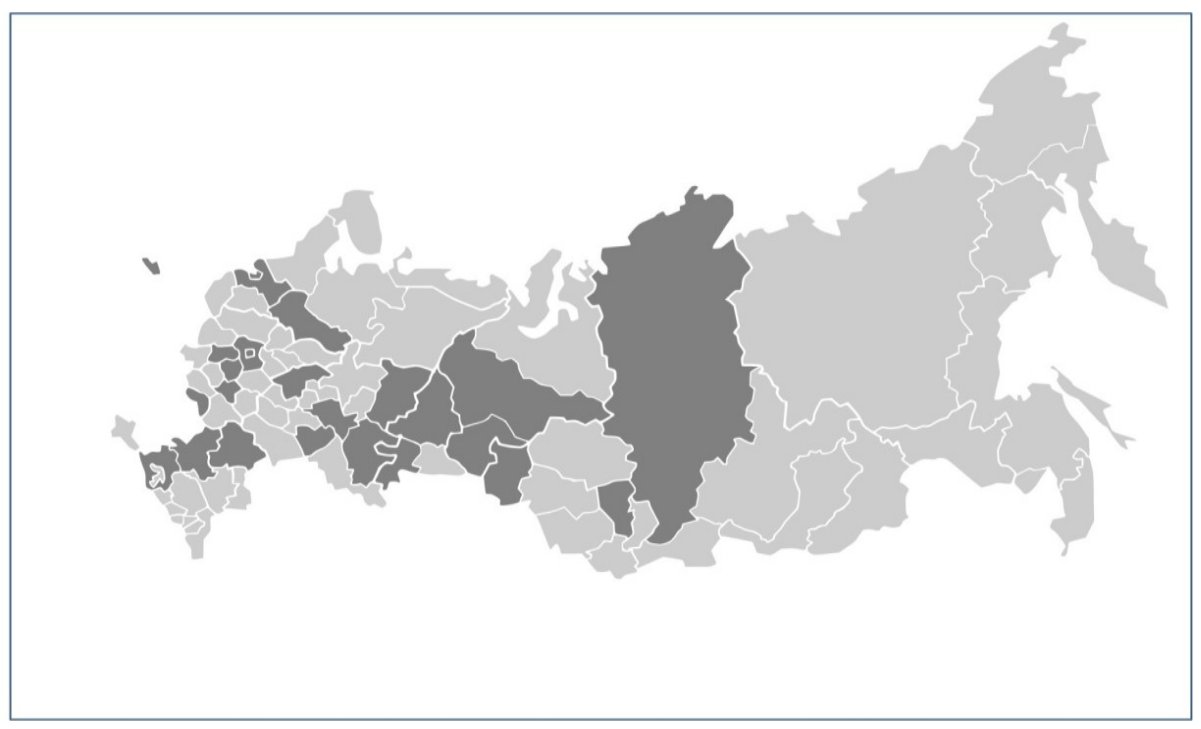

Fig. 1. Diagram of the values of the indicator of the degree of mutual influence of the Republic of Belarus with the constituent entities of the Russian Federation $L I S A_{1 j}$ (index 1 refers to the Republic of Belarus, index $j$ refers to the regions of the Russian Federation) in the manufacturing industry for 2018 Explanations are provided in the text.

\subsection{Determinants of spatial interaction between the regions of the Russian Federation and the Republic of Belarus}


The regression analysis of the influence of various factors on the normalized indicator $L I S A_{1 j}$ was carried out using the Beta regression described in section 2. The most significant economic, infrastructural, and institutional factors were evaluated as possible explanatory variables used in the regression analysis and influencing the normalized indicator $\operatorname{LISA}_{1 j}$ (table 1).

Table 1. The designation and description of explanatory variables used in regression analysis.

\begin{tabular}{|l|l|}
\hline \multicolumn{1}{|c|}{ Variable } & \multicolumn{1}{c|}{ Description } \\
\hline$\Delta(\ln Z P)$ & The difference between the logarithms of real wages per capita, rub. \\
\hline$\Delta(\ln I O C)$ & $\begin{array}{l}\text { Difference between logarithms of investments in fixed assets per capita, } \\
\text { rub. }\end{array}$ \\
\hline$\Delta(\ln Z I N)$ & $\begin{array}{l}\text { The difference between the logarithms of research and development costs, } \\
\text { million rubles / 1000 people }\end{array}$ \\
\hline$\Delta(\ln U R B)$ & Difference between logarithms of urban saturation (\%) \\
\hline$\Delta(\ln P O P)$ & The difference between the logarithms of the population (thousand people) \\
\hline$\Delta(\ln E R P)$ & $\begin{array}{l}\text { The difference between the logarithms of the number of registered crimes } \\
\text { per 10,000 people }\end{array}$ \\
\hline$\Delta(\ln V O B R)$ & $\begin{array}{l}\text { The difference between the logarithms of the percentage of employees } \\
\text { with higher education in the total structure of employees }\end{array}$ \\
\hline$(\ln R A S)$ & $\begin{array}{l}\text { Logarithm of the distance from the centers of the regions of the Russian } \\
\text { Federation with the center of the Republic of Belarus (km) }\end{array}$ \\
\hline$\Delta(\ln P L G D)$ & $\begin{array}{l}\text { The difference between logarithms of the density of public railway tracks } \\
\text { per 10,000 km2 on average per year }\end{array}$ \\
\hline$\Delta(\ln P L A D)$ & $\begin{array}{l}\text { The difference between the logarithms of the density of public roads per } \\
10,000 \text { km2 on average per year }\end{array}$ \\
\hline $\begin{array}{l}\text { Note: all variables (except for the distance from the centers of the regions) are defined in the } \\
\text { differences between the corresponding variables of the regions of the Russian Federation with the } \\
\text { Republic of Belarus. }\end{array}$
\end{tabular}

Thus, the functional connection between the dependent and explanatory variables is expressed as

$$
\begin{gathered}
L I S A_{1 j}=f(\Delta(\ln Z P), \Delta(\ln I O C), \Delta(\ln Z I N), \Delta(\ln U R B), \Delta(\ln P O P), \\
\Delta(\ln E R P), \Delta(\ln V O B R),(\ln R A S), \Delta(\ln P L G D), \Delta(\ln P L A D)) .
\end{gathered}
$$

The parameters of the regression equation approximating the functional connection (3) were assessed using the maximum likelihood method. Functions $g\left(\mu_{x}\right)$ and $h\left(\psi_{x}\right)$ were selected using the Bayesian Information Criterion $(B I C)$. The logistic function $g\left(\mu_{x}\right)$ and the logarithmic function $h\left(\psi_{x}\right)$ turned out to be the best choice. The results of estimating the parameters of the regression equation for the indicator $L I S A_{1 j}$ obtained based on the weight matrix of inverse linear distances and the matrix of economic activity of the regions are shown in Table 2. 
Table 2. Beta regression results

\begin{tabular}{|c|c|c|}
\hline Explanatory variables & $\begin{array}{l}\text { Estimation of coefficients } \\
\text { (inverse distance matrix) }\end{array}$ & $\begin{array}{c}\text { Estimation of coefficients } \\
\text { (matrix } \\
\text { of economic activity) }\end{array}$ \\
\hline$\Delta(\ln Z P)$ & $\begin{array}{l}0.019 \\
(0.069)\end{array}$ & $\begin{array}{r}0.009 \\
(0.019) \\
\end{array}$ \\
\hline$\Delta(\ln I O C)$ & $\begin{array}{r}-0.073 \\
(0.067) \\
\end{array}$ & $\begin{array}{r}-0.033 \\
(0.032) \\
\end{array}$ \\
\hline$\Delta(\ln Z I N)$ & $\begin{array}{c}0.158^{* * *} \\
(0.053)\end{array}$ & $\begin{array}{l}0.291^{* * *} \\
(0.041)\end{array}$ \\
\hline$\Delta(\ln U R B)$ & $\begin{array}{c}-0.133^{* *} \\
(0.053)\end{array}$ & $\begin{array}{c}-0.331^{* * *} \\
(0.081)\end{array}$ \\
\hline$\Delta(\ln P O P)$ & $\begin{array}{l}-1.168^{* * * *} \\
(0.197)\end{array}$ & $\begin{array}{l}-1.191^{* * *} \\
(0.297)\end{array}$ \\
\hline$\Delta(\ln E R P)$ & $\begin{array}{r}-0.149 \\
(0.171) \\
\end{array}$ & $\begin{array}{r}-0.103 \\
(0.091) \\
\end{array}$ \\
\hline$\Delta(\ln V O B R)$ & $\begin{array}{c}-0.256^{* *} \\
(0.119) \\
\end{array}$ & $\begin{array}{c}-0.436^{* *} \\
(0.220)\end{array}$ \\
\hline$(\ln R A S)$ & $\begin{array}{c}-0.326^{* * *} \\
(0.122)\end{array}$ & $\begin{array}{c}-0.561^{* * *} \\
(0.211)\end{array}$ \\
\hline$\Delta(\ln P L G D)$ & $\begin{array}{c}-0.117 \\
(0.124)\end{array}$ & $\begin{array}{r}-0.038 \\
(0.029) \\
\end{array}$ \\
\hline$\Delta(\ln P L A D)$ & $\begin{array}{r}-0.037 \\
(0.044)\end{array}$ & $\begin{array}{r}-0.007 \\
(0.009)\end{array}$ \\
\hline \multicolumn{3}{|c|}{$\begin{array}{l}\text { Note: the significance level } * \text { corresponds to } 10 \% \text {, the significance level } * * \text { corresponds to } 5 \% \text {, } \\
\text { the significance level } * * * \text { corresponds to } 1 \% \text {. Standard deviations are shown in parentheses. } \\
\text { Dependent variable } L I S A_{1 j} \text {. }\end{array}$} \\
\hline
\end{tabular}

It should be noted that due to the heterogeneity of the sample of observations of the indicator $L I S A_{1 j}$, the regression analysis used a heteroscedasticity-resistant estimate of the covariance matrix of coefficients, taking into account clustering.

It is difficult to interpret the Beta regression coefficients due to the nonlinearity of the functional relationship (5). Therefore, we need to transform the coefficients in such a way as to get the following interpretation: changing the coefficient by 1 unit will lead to a change in the dependent variable by a certain number of percent. To do this, we can use the formula for the percentage change in the odd ratio, standard for binary choice models. The value $\mu_{x}=\frac{\exp \left(\mathbf{x}^{\prime} \beta\right)}{\left(1+\exp \left(\mathbf{x}^{\prime} \beta\right)\right.}$ follows from the view of the logistics function $g\left(\mu_{x}\right)=\log \left(\mu_{x} /\left(1-\mu_{x}\right)\right)$. It is easy to show that if the value of any regressor changes by $c$ units with the unchanged values of the other regressors, then the ratio of chances is

$$
\exp (c \hat{\beta})=\frac{\mu_{x}^{\text {new }} /\left(1-\mu_{x}^{\text {new }}\right)}{\mu_{x} /\left(1-\mu_{x}\right)}
$$


where $\hat{\beta}-$ is the estimated value of the parameter, $\mu_{x}^{\text {new }}, \mu_{x}--$ the conditional mathematical expectations of the dependent variable for the given values of the regressors after and before increasing the value of the regressor by $c$ units.

Taking into account (6), for $c=1$ and $c=0$

$$
\text { increase in odds ratio, } \%=(\exp (\hat{\beta})-1) \times 100 \text {. }
$$

For example, according to (5), an increase in the difference in the logarithms of the level of urbanization between the regions of the Russian Federation and the Republic of Belarus leads to a decrease in their degree of mutual influence $(\exp (0.133)-1) \times 100=$ by $14.2 \%$ (for the inverse distance matrix). The variable associated with the difference in the logarithms of the population has a more significant effect on the dependent variable $L I S A_{1 j}$. In this case, the increase in the difference in population also reduces the degree of mutual influence of the regions. A similar conclusion can be drawn for the variable related to the difference between the logarithms of the percentage of employees with higher education in the overall structure of employed people.

An interesting result is that the difference between the logarithms of real wages per capita between the regions of the Russian Federation and the Republic of Belarus does not affect the degree of possible mutual influence of the regions. Since real wages are related to the level of prices in the constituent entities, the latter does not affect the possible interaction of regions. The difference between the logarithms of research and development costs has a positive impact on the interaction between the regions of the Russian Federation and the Republic of Belarus, which indicates that the dissemination of knowledge is the driver of regional interaction.

As follows from Table 2, the control variables associated with the infrastructure of the regions of the Russian Federation and the Republic of Belarus, such as the logarithm of the difference between the densities of public railways, the logarithm of the difference between the densities of public highways, do not affect the degree of interaction between regions. But the distance between the centers of the regions of the Russian Federation and the Republic of Belarus affects their possible interaction. Also, such factors as the difference between the logarithms of investments in fixed assets per capita and the difference between the logarithms of the number of registered crimes do not affect the possible mutual influence of the regions of the Russian Federation and the Republic of Belarus.

The results of estimating the Beta regression coefficients based on an economically active weight matrix for indicator $L I S A_{1 j}$ differ significantly from the results obtained using the inverse linear distance matrix. At the same time, the numerical values of the significant coefficients when using an economically active weight matrix exceed the similar values of the coefficients obtained when using the inverse distance matrix. This is most likely due to a more homogeneous sample of the indicator observations $\operatorname{LISA} A_{i j}$.

\section{Conclusions}

This paper estimated the levels of possible interterritorial interaction between the regions of the Russian Federation and the Republic of Belarus in the field of manufacturing industry and investigated the factors influencing this interaction. 
The spatial features of the distribution of output in the manufacturing sector among the territories of Russia and Belarus are estimated by the spatial autocorrelation method (using Moran indices). The studies performed and the obtained estimates of the global and local indices for territories of various types confirm the applicability of Moran's indices for solving the task of determining the distribution of the studied indicator between the territories of Russia and Belarus. The influence of economic, infrastructural, and institutional factors has been studied. The influence of explanatory variables (economic, infrastructural, and institutional factors) on the level of possible interaction between the regions of the Russian Federation and the Republic of Belarus in the manufacturing industry is studied using Beta regression.

Meaningful interpretation is given by the obtained simulation results. The results of the work provide an opportunity to monitor economic relations and find promising areas for their activation using spatial autocorrelation models and econometric modeling. The expansion of the model and methodological tools for studying the interaction of the macroregions of Russia with the territorial entities of the Republic of Belarus may be the direction of further research. The work results can be used by public authorities when forming plans for the development of a global partnership between the Russian Federation and the Republic of Belarus.

\section{Acknowledgements}

This article was prepared under the approved research plan of the Institute of Economics of the Ural Branch of the Russian Academy of Sciences.

\section{References}

1. K. A. Gulin, S. M. Dedkov, V. S. Uskov, Economic and social changes: facts, trends, forecast, 4, 32 (2013)

2. P.A. Minakir, Economy of the Region, 15(4), 967 (2019)

3. M.B. Petrov, L.A. Serkov, K.B. Kozhov, Development Strategy of the Economy of Belarus: Challenges, Implementation Tools and Prospects, 177 (2020)

4. M.N. Makarova, Economic and social changes: facts, trends, forecast, 14(2), 29 (2021)

5. P. Moran, Biometrika, 37, 17 (1950)

6. S. L. P. Ferrari , F. Cribari-Neto, Journal of Applied Statistics, 31, 799 (2004) 